\title{
Coronally Repositioned Flap with Bioresorbable Collagen Membrane for Miller's Class I and II Recession Defects: A Case Series
}

\author{
Mrinalini Agarwal ${ }^{\mathrm{a}}$ Deepa Dhruvakumar ${ }^{\mathrm{b}}$ \\ a Department of Periodontology, Subharti Dental College and Hospital, Swami Vivekanand Subharti University, \\ Meerut, India; ${ }^{b}$ Department of Periodontology, Teerthanker Mahaveer Dental College and Research Centre, \\ Teerthanker Mahaveer University, Moradabad, India
}

\section{Significance of the Study}

- Guided tissue regeneration-based root coverage procedures have emerged as an attractive treatment as they provide similar results to those of traditional techniques but also histologically demonstrate new attachment formation. This study evaluates the efficacy of recession coverage using a coronally repositioned flap in conjunction with a bioresorbable collagen membrane.

\section{Keywords}

Recession · Collagen membrane · Guided tissue

regeneration · Miller's Class I and II recession

\begin{abstract}
Objective: Gingival recession is one of the most common esthetic and functional concerns associated with periodontal tissues. Several techniques have been described to cover the exposed root surface. The aim of the present study was to evaluate the efficacy of recession coverage using a coronally repositioned flap in conjunction with a bioresorbable collagen membrane. Methods: Eight non-smoking healthy subjects with Miller's Class I and II recession defects in the maxillary anterior region were selected. Recession was treated by a coronally repositioned flap along with a bioresorbable type I collagen guided tissue regeneration membrane $\left(\right.$ Periocol $\left.{ }^{\circledR}\right)$. Clinical parameters recorded were recession depth, recession width, width of keratinized tissue, and width of the attached gingiva at baseline and 3 months post-
\end{abstract}

\begin{tabular}{ll}
\hline KARGER & $\begin{array}{l}\text { (c) 2019 The Author(s) } \\
\text { Published by S. Karger AG, Basel Openger }\end{array}$ \\
E-Mail karger@karger.com & $\begin{array}{l}\text { This is an Open Access article licensed under the Creative Commons } \\
\text { Attribution-NonCommercial-4.0 International License (CC BY-NC) } \\
\text { (http://www.karger.com/Services/OpenAccessLicense), applicable to } \\
\text { the online version of the article only. Usage and distribution for com- } \\
\text { mercial purposes requires written permission. }\end{array}$
\end{tabular}

operatively. Results: Three-month postoperative measurements demonstrated significant root coverage and a reduction in the recession depth and width. In addition, there was a significant increase in the width of keratinized tissue and of the attached gingiva. Conclusion: Recession coverage with a coronally repositioned and bioresorbable collagen membrane demonstrated good results in terms of root coverage as well as increase in the width of keratinized tissue.

(c) 2019 The Author(s)
Published by S. Karger AG, Basel

\section{Introduction}

Gingival recession is defined as the exposure of the root surface by an apical shift in position of the marginal gingiva [1]. It is a widespread clinical manifestation and may affect single or multiple root surfaces. The most common cause of gingival recession is faulty tooth brushing; however, other predisposing factors include 
dental plaque, high frenum pull, area of root prominence, thin narrow band of gingiva, iatrogenic factors, and postsurgical gingival recessions. Root hypersensitivity, esthetic problems, and abrasion may accompany gingival recession and may be detrimental to overall dental health [2].

Guided tissue regeneration (GTR) is based on the principle of epithelial exclusion or compartmentalization. It consists of placing a barrier membrane between the surgical flap and the root surface to prevent the gingival epithelial cell and connective tissue from interfering in the root surface during healing [3]. Research conducted on type I collagen has proven its effectiveness for use as a barrier membrane [4]. Periocol ${ }^{\circledR}$ is a fibrillar sterile bioresorbable collagen GTR membrane of fish origin, manufactured by Eucare Pharmaceuticals (Chennai, India) and has been used in this study. The present study was conducted to evaluate the efficacy of bioresorbable collagen membrane in conjunction with a coronally repositioned flap (CRF) for the treatment of Miller's Class I and II recession defects.

\section{Materials and Methods}

Eight subjects, six males and four females between 20 and 50 years of age, presenting with Miller's Class I/II gingival recession in maxillary anterior teeth were included in the study.
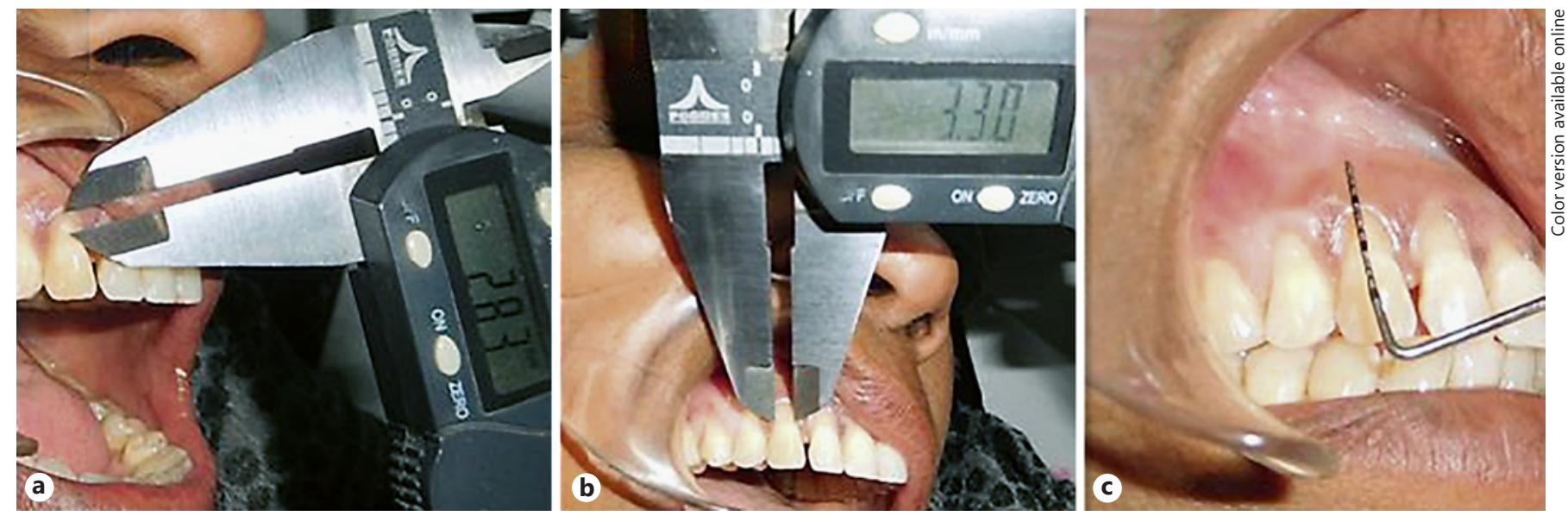

Fig. 1. Preoperative RD (a), preoperative RW (b), and preoperative width of KT (c).

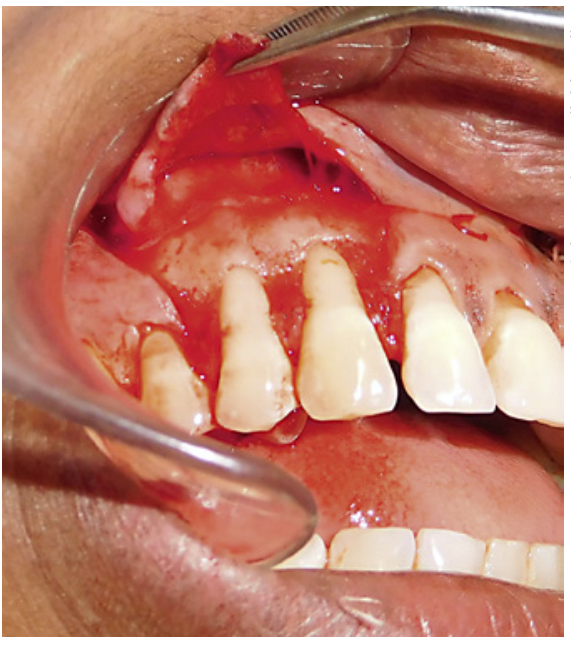

Fig. 2. Incisions and flap reflection.

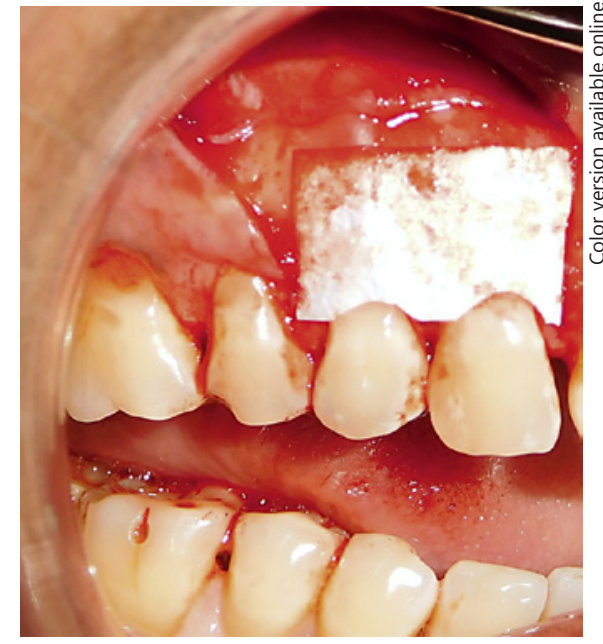

Fig. 3. Placement of the bioresorbable collagen membrane (Periocol).

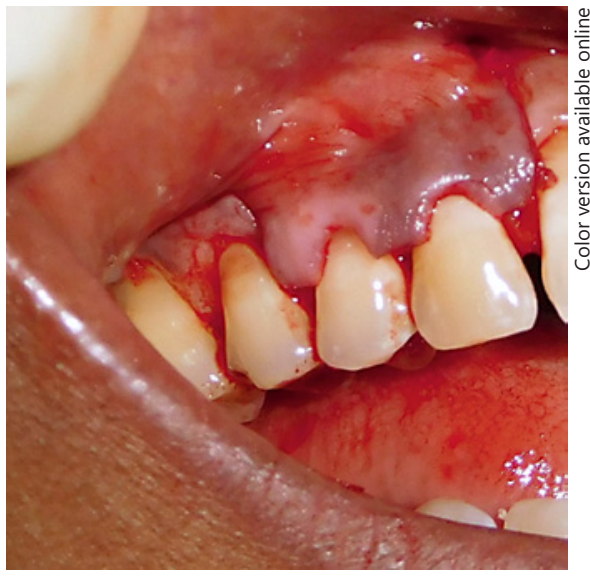

Fig. 4. Flap repositioned coronally. 
Inclusion criteria were: systemically healthy individuals, compliant patients, maxillary anterior teeth with Miller's Class I, or II facial recession defects [5].

Exclusion criteria were: smokers, pregnant and lactating females, tooth not properly aligned in the arch, tooth associated with trauma from occlusion (TFO), cervical abrasion, and restorations.

All subjects were subjected to phase I therapy, which included scaling and root planing. Later, the surgical procedure was explained, and a written informed consent was signed by each patient before initiation of the surgical therapy. A CRF with a bioresorbable Periocol GTR membrane was used for the coverage of recession defects.

The following clinical parameters were recorded using UNC15 periodontal probe and digital vernier calipers at baseline (before surgery) and 3 months after surgery (Fig. 1a-c): recession depth (RD), recession width (RW), width of keratinized tissue (KT), width of the attached gingiva (AT).

\section{Surgical Protocol}

The surgical site was anesthetized with local anesthetic solution (lignocaine hydrochloride $2 \%$ with adrenaline 1:200,000). Intrasulcular incisions were horizontally extended to the adjacent papil- lae avoiding the gingival margin of the adjacent teeth on the buccal side of the involved tooth. Two oblique releasing incisions were carried beyond the mucogingival junction. A trapezoidal fullthickness flap was raised with a periosteal elevator (Fig. 2). Then, a partial-thickness dissection was carried out apically, leaving the underlying periosteum in place. In addition, a mesiodistal and apical dissection parallel to the vestibular lining mucosa was performed to release residual muscle tension and to facilitate the passive coronal displacement of the flap. The papillae adjacent to the involved tooth were de-epithelized, and the root surface was then planed thoroughly. A resorbable collagen membrane (Periocol) was trimmed to obtain the required size with the help of a template and was then placed over the denuded root surface extending from CEJ to 2-3 mm both laterally as well as apically (Fig. 3). The flap was coronally repositioned to cover the membrane completely, and oblique releasing incisions were sutured with 5-0 ethicon nonresorbable sutures (Fig. 4, 5). Periodontal pack was placed over the surgical site. Patients were prescribed an antibiotic (amoxicillin $500 \mathrm{mg}$, three times daily) and an analgesic (ibuprofen $600 \mathrm{mg}$, twice daily) for 7 days. Furthermore, $0.2 \%$ chlorhexidine gluconate rinses were advised twice daily for 3 weeks. After 10 days, the periodontal pack and sutures were removed.

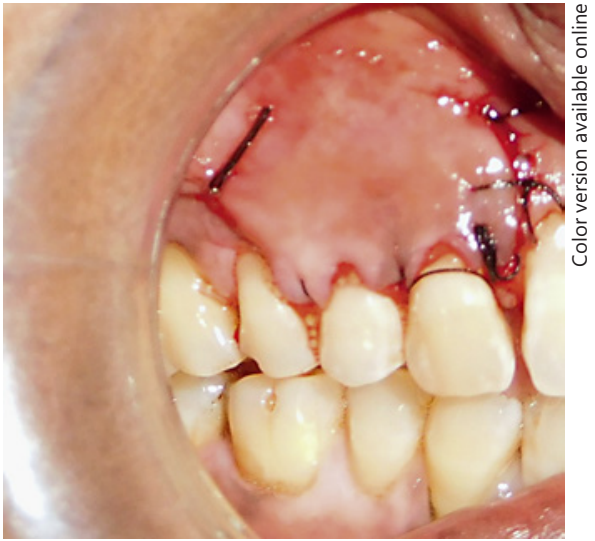

Fig. 5. Sutured incisions.

\section{Results}

Patients were recalled after 3 months for follow-up, and the clinical parameters were recorded (Fig. 6a-c). Data thus obtained were subjected to statistical analysis. The statistical analysis was done using Student's paired $t$ test. The significance level was set at $p \leq 0.05$. The mean value of RD pre- and postoperatively was recorded as 2.78 and $1.51 \mathrm{~mm}$, respectively. Similarly, the mean value of RW pre- and postoperatively was recorded as 3.70 and $3.15 \mathrm{~mm}$, respectively. The mean value of width of $\mathrm{KT}$ pre- and postoperatively was recorded as 5.00 and 6.13
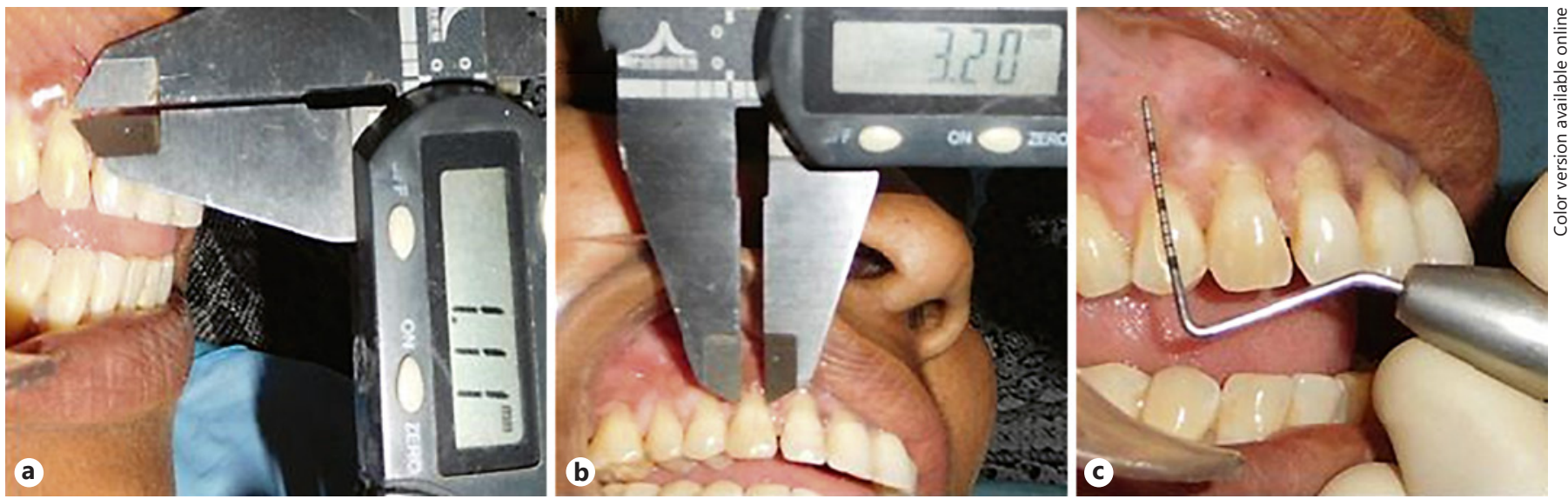

Fig. 6. Postoperative RD (a), postoperative RW (b), and (c) postoperative width of KT. 
Table 1. Mean and standard deviation of clinical parameters at baseline and 3 months postoperatively

\begin{tabular}{lllll}
\hline Parameters & Pre-op & Post-op & Difference & $p$ value \\
\hline RD & $2.78 \pm 0.51$ & $1.81 \pm 0.61$ & $0.97 \pm 0.57$ & 0.0018 \\
RW & $3.70 \pm 0.56$ & $3.15 \pm 0.47$ & $0.55 \pm 0.30$ & 0.0013 \\
KT & $5.00 \pm 0.76$ & $6.13 \pm 0.99$ & $1.13 \pm 0.83$ & 0.0066 \\
AT & $3.50 \pm 0.93$ & $5.25 \pm 1.28$ & $1.75 \pm 1.04$ & 0.0020 \\
\hline
\end{tabular}

$\mathrm{mm}$, respectively, and for the width of AT, the mean value recorded pre- and postoperatively was 3.50 and 5.25 $\mathrm{mm}$, respectively. For all clinical parameters, the $p$ value was found to be statistically significant (Table 1).

\section{Discussion}

The predictable root coverage remains an elusive goal of the reconstructive periodontal therapy. Varieties of periodontal plastic procedures have been developed for treatment of gingival recessions. Pini Prato et al. [6] have demonstrated the effectiveness of a barrier membrane in the treatment of human facial gingival recession. Roccuzzo et al. [7] reported a lack of marked difference in results between bioresorbable and nonresorbable membranes but suggested that the single-step surgical procedure was preferable.

The results of this study are both clinically and statistically significant. Membrane exposure did not occur in any of the 8 cases. The maintenance of attachment is influenced by postoperative inflammation, hence proper oral hygiene by the patient is an important factor to avoid chances of postoperative recession. The GTR membrane may also serve to relieve the functional stresses on the gingival flap, which might otherwise disrupt the fragile adhesions of the maturing fibrin clot to the root during the early surface and most critical phase of healing [8].

Periocol is a bioresorbable collagen membrane of fish origin, developed for GTR application [9]. Collagen is hemostatic, possesses an ability to stimulate platelet attachment, and enhances fibrin linkage, which may facilitate initial clot formation and stabilization, leading to enhanced regeneration It has also has been found to be chemotactic for fibroblasts in vitro and thus may enhance cell migration. Another useful benefit of collagen is that it might augment the tissue volume as it is naturally absorbed and replaced by host tissue [10]. The promising results in terms of root coverage and increased amount of keratinized gingiva achieved in this study may help in further research in gingival recession treatment.

\section{Conclusion}

Proper surgical technique, aseptic conditions, and postoperative care are the keys to successful management of these cases. However, controlled studies with longterm follow-up are required to compare the efficacy of $\mathrm{CRF}$ procedures in conjunction with a bioresorbable membrane for more meaningful conclusions.

\section{References}

1 American Academy of Periodontology. Glossary of Periodontal terms. 3rd ed. Chicago: American Academy of Periodontology; 1992.

2 Löe H, Anerud A, Boysen H; The American Academy of Periodontology. The natural history of periodontal disease in man: prevalence, severity, and extent of gingival recession. J Periodontol. 1992 Jun;63(6):489-95.

3 Gottlow J, Nyman S, Karring T, Lindhe J. Treatment of localized gingival recession with coronally displaced flaps and citric acid. An experimental study in the dog. J Clin Periodontol. 1986;13(1):57-63.

4 Jain D, Deepa D. A comparative evaluation of freeze-dried bone allograft with and without bioabsorbable guided tissue regeneration membrane Healiguide $\left({ }^{\circledR}\right)$ in the treatment of Grade II furcation defects: A clinical study. J Indian Soc Periodontol. 2015 Nov-Dec;19(6): 645-50.
5 Miller PD Jr. A classification of marginal tissue recession. Int J Periodontics Restorative Dent. 1985;5(2):8-13.

6 Pini Prato G, Clauser C, Cortellini P, Tinti C, Vincenzi G, Pagliaro U. Guided tissue regeneration versus mucogingival surgery in the treatment of human buccal recessions. A 4-year follow-up study. J Periodontol. 1996 Nov;67(11):1216-23.

7 Roccuzzo M, Lungo M, Corrente G, Gandolfo S. Comparative study of a bioresorbable and a non-resorbable membrane in the treatment of human buccal gingival recessions. J Periodontol. 1996 Jan;67(1):7-14.
8 Cortellini P, Pini-Prato G, Tonetti M. Periodontal regeneration of human infrabony defects $(V)$. Effect of oral hygiene on long-term stability. J Clin Periodontol. 1994 Oct;21(9): 606-10.

9 Prathap S, Hegde S, Kashyap R, Prathap MS, Arunkumar MS. Clinical evaluation of porous hydroxyapatite bone graft (Periobone G) with and without collagen membrane (Perio$\mathrm{col}$ ) in the treatment of bilateral grade II furcation defects in mandibular first permanent molars. J Indian Soc Periodontol. 2013 Mar; 17(2):228-34.

10 Boltchi FE, Allen EP, Hallmon WW. The use of a bioabsorbable barrier for regenerative management of marginal tissue recession. I. Report of 100 consecutively treated teeth. J Periodontol. 2000 Oct;71(10):1641-53. 